\title{
Painful Tonic Seizures in Multiple Sclerosis: Localization of a Lesion
}

\author{
C. PETER WATSON, M.CHIU
}

SUMMARY: The history of a patient with painful tonic seizures in association with multiple sclerosis is related. These seizures have been thought by most authors to be spinal in origin. This case is reported because of the localization of a supratentorial lesion, clinically and on CT scan.

RESUME: Crises toniques douloureuses dans la Sclérose en plaques: localisation d'une lésion.

Nous relatons l'histoire d'un patient atteint de sclérose en plaques qui souffrait de crises toniques douloureuses. Ces crises ont été considérées par la majorité des auteurs comme étant d'origine spinale. Nous rapportons le présent cas à cause de la localisation supratentorielle de la lésion. tel que montré cliniquement et confirmé par tomodensitométrie cérébrale.

From The Mississauga Hospital. Mississauga and The Toronto Western Hospital, Toronto, Ontario.

Reprint requests to: Dr. C. P. Watson, 3025 Hurontario Street, \#504, Mississauga, Ontario. L5A 2HI. Canada.

\section{INTRODUCTION}

The association of painful tonic seizures and multiple sclerosis was first established by Matthews (1958) and is now well recognized. (Joynt, 1962; Shibasaki, 1974; Osterman, 1975; Tokoyura, 1976). Earlier reports described tonic seizures in cases of probable multiple sclerosis. (Determann, 1892; Guillain, 1928; Redlich, 1929; Decourt, 1938; Storring, 1940; Arnould, 1958). The localization of lesions responsible for this disorder is unclear from clinical and autopsy material. This report describes the clinical and CT scan localization of a lesion in the right internal capsule.

\section{CASE HISTORY}

This 32 year old woman's history began in 1965. She had a three week episode of numbness and mild weakness of her legs up to the groin in the post partum period lasting three weeks.

She was first seen here in January, 1970 with a bilateral internuclear ophthalmoplegia which cleared in four weeks. Her C.S.F. at that time showed a gamma globulin of $20 \%$, total protein of $60 \mathrm{mgms}$ and 10 lymphocytes per cubic millimitre.

In July, 1975 she was seen with a left sixth nerve palsy, a mild left facial weakness of a peripheral type, and left facial myokymia. She also had a spinothalamic sensory loss over the contralateral thorax distally to involve the leg. She was treated with glucocorticoids and recovered over two weeks.

In November, 1975 she was seen with numbness of the left face which involved pain and temperature and left facial myokymia. She had spino- thalamic sensory loss of the right arm. This cleared within two weeks.

On August 14th, 1978 she presented with painful loss of vision, weakness and paresthesiae of the left face, arm, and leg. The physical findings revealed visual acuity of 20/200 in both eyes. She had bilateral central scotomata and a left homonymous hemianopia. There was a left lower facial weakness and weakness of the left arm and leg Grade $4+$ in the usual distribution of an upper motor neuron lesion, with increased reflexes and a left upgoing toe, but no sensory findings.

These findings remained and two weeks later she presented with the onset of painful spasms involving the left face, arm, and leg. These would occur every 10 to 15 minutes and last up to two minutes. They involved spasm of the muscles of the left lower face which pulled the lower facial musculature to the left and up. They involved spasm of the left arm with adduction of the shoulder, flexion of the elbow to about $90^{\circ}$, flexion of the wrist to $90^{\circ}$, flexion of the metacarpophalangeal joints to about $110^{\circ}$ with extension of the fingers and thumb. (fig. 1) With some attacks the thumb was noted to protrude between the middle two fingers with the finger slightly flexed. (fig. 2) The lower extremity was slightly flexed at the hip, flexed to $100^{\circ}$ at the knee, and the foot was plantar flexed and inverted. (fig. 1) These spasms were provoked by tactile stimulation of the hand, by noises such as the telephone ringing, spontaneously, by emotional stimuli, and by hyperventilation during an E.E.G. recording. The E.E.G. showed no epileptic activity during the spasm or at other times. There was no ante- 


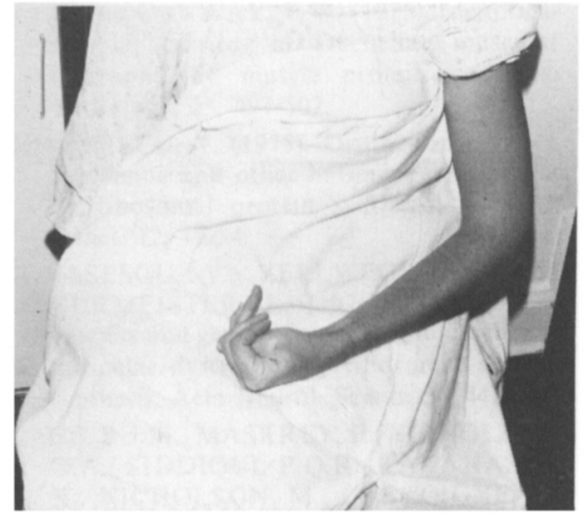

Figure l: Alternate hand posture observed with some seizures. The thumb protrudes between the middle two fingers and all fingers are flexed rather than extended.

cedent sensory disturbance with the spasms, as there had been with the initial deficit two weeks before, but pain accompanied most of the spasms which appeared to begin in the hand. A CT scan performed at this time demonstrated a lesion in the right internal capsule. (fig. 3). This lesion was thought to involve the posterior one-third of the lenticulothalamic portion and the retrothalamic portion of the right internal capsule, and hence accounted for the left hemi-

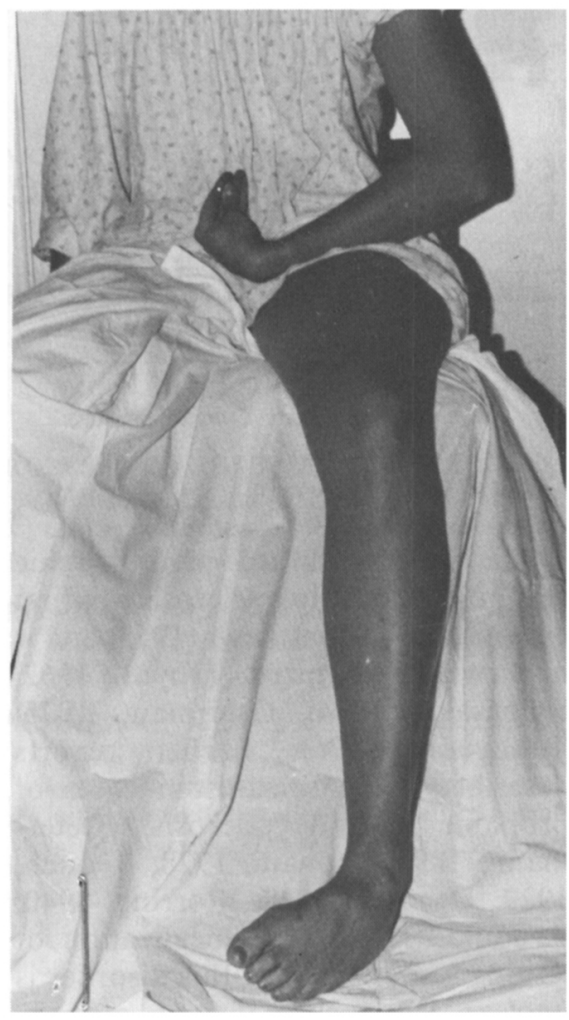

Figure 2 - Limb posture observed in this case of painful tonic seizures and multiple sclerosis.

paresis and left homonymous hemianopia and likely also explained the tonic spasms. For one week the patient continued to suffer the attacks while on phenytoin $300 \mathrm{mgs}$. daily. She was then placed on carbamazepine 200 mgs. t.i.d. and within 24 hours the spasms disappeared and have not returned. She has now been off carbamazepine for one month, having taken it for four weeks.

\section{DISCUSSION}

Painful tonic seizures consist of episodes of uncontrollable, usually painful postures of one, two, three, or four limbs lasting up to two minutes and often occurring up to 40 times a day. In Matthews' original article (1958) he described the posturing as resembling tetany, but later (1975) modified this view when it became apparent that although the attacks in an individual were stereotyped there was a great variability in limb position amongst individuals. Postures in this case (figures 1 and 2) most closely resemble the early cases described by Matthews (1958) and the resemblance to tetany is apparent. Pain is a common but not invariable accompaniment of the spasms and both symptoms may progress and march from a triggered site (Matthews, 1958). The attacks may be spontaneous, but
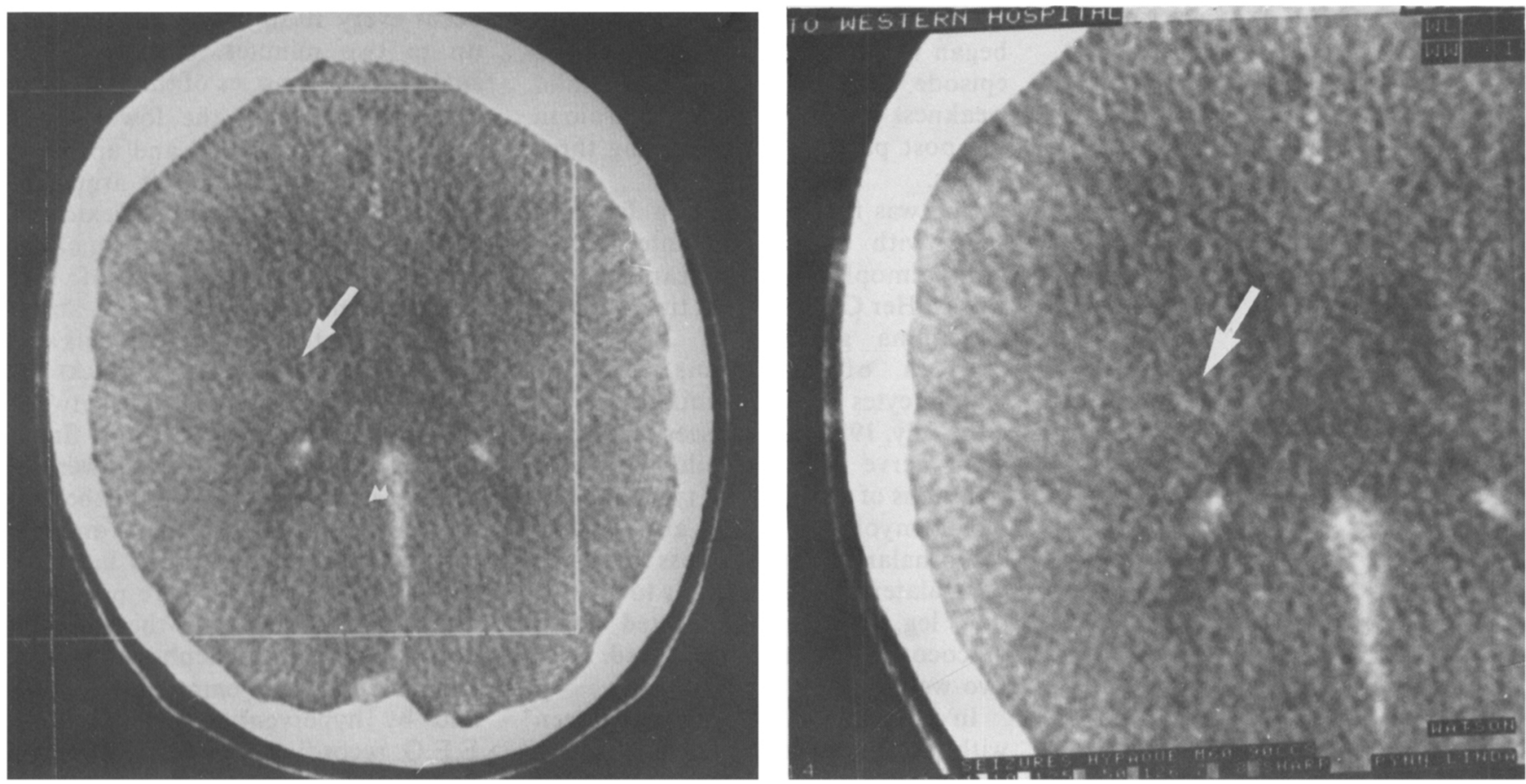

Figure 3 - After intravenous hypaque, enhancement of a low density area in the right internal capsule was demonstrated. 
are often triggered by tactile stimulation, limb movement, noise, or air movement (Matthews, 1958). Hyperventilation is a well recognized precipitating factor, further suggesting tetany (Matthews, 1958). The E.E.G. is usually normal and attacks have, as in our case, been captured during E.E.G. recording with and without hyperventilation, with no ictal activity demonstrated. (Matthews, 1958; Toyokura, 1976).

Although the natural history of painful tonic seizures is one of remission, phenobarbital (Matthews, 1958), phenytoin (Matthews, 1958), and carbamazepine have been found to be useful in treatment. More success has been recorded with carba mazepine in this and other paroxysmal symptoms in multiple sclerosis. (Miley, 1974; Shibasaki, 1974; Matthews, 1975; Osterman, 1975; Toyokura, 1976). With our case, relief was obtained within 24 hours of starting carbamazepine, after the failure of phenytoin.

Guillain (1928) and others (Storring, 1940) thought these attacks were epileptic. Matthews (1958) thought they were mesencephalic focal seizures. Kreindler (1962) felt tonic seizures were due to lesions in the caudal reticular formation.

More recently, Osterman (1975) has suggested that the spells result from "transversely spreading ephaptic activitation of axons within a partially demyelinated lesion in fibre tracts somewhere in the central nervous system".

Clinical and autopsy studies have been uniformly unhelpful in clearly demonstrating a lesion site responsible for any given attack. A number of authors (Schnabl, 1897; Oppenheim,
1899: Matthews, 1958: Castaigne, 1970; Kreindler, 1962; Kuroiwa, 1963; Kuroiwa, 1968; Shibasaki, 1974) have thought the attacks were spinal in origin because of the predominance of spinal symptoms, signs, and autopsy lesions. Others (Osterman, 1975) have allowed that a lesion at any level of the neuraxis was capable of producing the phenomonon.

It seems reasonable that the clinical localization of the acute lesion in this case, which occurred one week prior to the onset of the spasms, can be correlated with the involvement observed during the spasms and with the lesion demonstrated by CT scan, which was performed at the time of the spasms. This case demonstrates that a supratentorial lesion at the level of the internal capsule is capable of producing painful tonic seizures in multiple sclerosis.

\section{REFERENCES}

ARNOULD, G., HARTEMANN, P., DUREUX, J. B., TRIDON, P., SCHMITT, J. (1958) Sclerose en plaques et tetanie. Des tetanies neurogenes. Revue Neurol. 98: 297300.

CASTAIGNE, P., CAMBIER, J., MASSON, M., BRUNET, P., LECHEVALLIER, B., DELAPORTE, P., DEHEN, H. (1970) Les manifestations motrices paroxystiques de la sclerose en plaques. Press. Med., 78, 19211924.

DECOURT, J. (1938) A propos d'un cas d'hem:tetanie d'origine cerebrale. Considerations sur la physiopathologie de la tetanie. Revue neurol. 70, 94-98.

DETERMANN, H. (1892) Zwei Falle von Ruckenmarkserkrankung nach Influenza. Dt. Z. NervHeilk. 2, 106-112.

GUILlAIN, G.. ALAJOUANINE, TH., BERTRAND, I., GARCIN, R. (1928) Sur une forme anatomoclinique speciale de neuromyelite optique necrotique aigue a vec crises toniques tetanoides. Annis. Med., 24, 24-57.
JOYNT, R. J., GREEN, D., (1962) tonic seizures as a manifestation of multiple sclerosis. Arch. Neurol. 6: 293-299.

KREINDLER, A.. CARDAS, M., PETRESCO, AR. . BOTEZ. M. I. (1962) Considerations sur l'entiopathogenie des crises toniques dans l'encephalomyelite disseminee. Revue. Neurol. 107, 353-369.

KUROIWA, Y., ARAKI, S. (1963) Lhermitte's sign and reflex tonic spasm in demyelinating diseases with special reference to their localizing value. Kyushu J. Med. Sc. 14, 29 38.

KUROIWA, Y., SHIBASAKI, H. (1968) Painful tonic seizures in multiple sclerosis. Treatment with diphenylhydantoin and carbamazepine. Folia psychiat. neurol. jap. 22, 107-119.

MATTHEWS, W. B., (1958) Tonic seizures in disseminated sclerosis. Brain, 81: 193-206.

MATTHEWS. W. B., (1975) Paroxysmal symptoms in multiple sclerosis. Jnl. Neurol. Neurosurg. Psych. 38: 617-623.

MILEY, C. E., FORSTER, F. M. (1974) Paroxysmal signs and symptoms in multiple sclerosis. Neurolog. (Minneap) 24:458-461.

OPPENHEIM, H. (1899) Zur Brown-Sequard schen Lahmung. Arch. Anat. Physiol. Suppl. 15, 1-30.

OSTERMAN, P. O., WESTERBERG, C. E., (1975) Paroxysmal Attacks in Multiple Sclerosis. Brain, 98: 189-202.

REDLICH, E., (1929) Zur Klinik der Hemitetanie mit Erorterungen uber den Auslosungort der tetanischen $\mathrm{Krampfe}$. Z. ges. Neurol. Psychiatr. 120: 236-264.

SCHNABL, J. (1897) Wiener medicinischer Club. Sitzung vom 24. Wien. Klin. Wschr. 10. $1112-1113$

SHIBASAKI, H., KUROIWA. Y.. (1974) Painful tonic seizures in multiple sclerosis. Arch Neurol. Chicago, 30: 47-51.

STORRING, G. E., (1940) Epilepsie und multiple Sklerose: Zugleich ein Beitrag zur Differentialdiagnose der Epilepsie. Arch. Psychiatr. NervKrankh., 112, 45-75.

TOKOYURA, Y., SAKUTA, M., NAKANISHI. T., (1976) Painful tonic seizures in multiple sclerosis. Neurology, June 1976. Part 2. 